\title{
A ESTRADA DA MATA E A INTEGRAÇÃO REGIONAL PELO INTERIOR DO BRASIL MERIDIONAL
}

\author{
Alcides Goularti Filho'
}

\begin{abstract}
Resumo
O objetivo deste artigo é descrever e analisar a integração do Brasil meridional pelo interior, a partir da abertura e dos melhoramentos da Estrada da Mata, localizada no planalto norte- catarinense e sudeste paranaense, de Lages (SC) a Campo do Tenente (PR), que era parte integrante dos caminhos das tropas entre Viamão e Sorocaba. Discutiremos a trajetória dessa Estrada desde o início de seus melhoramentos, em 1829, passando pelo seu abandono, no final do século XIX e início do XX, até a inclusão do seu traçado mais geral no Plano de Viação de 1944, que culminou com a abertura de uma nova rodovia toda pavimentada entre Curitiba e Lages, inaugurada em 1959. O artigo está divido em quatro tópicos: a) expansão das fronteiras e abertura de caminhos; b) obras e melhoramentos na Estrada da Mata; c) a chegada das ferrovias e o abandono da Estrada; e d) a velha estrada e a nova rodovia.
\end{abstract}

Palavras-chaves: Estradas, história, economia, integração, tropeirismo.

Classificação JEL: N7; R41.

\section{EXPANSÃO DAS FRONTEIRAS E ABERTURA DE CAMINHOS}

A ocupação e a expansão territorial para o sul da Colônia, no século XVII, tiveram início ainda no Período Filipino (1580-1640) e se intensificaram com as disputas entre Portugal e Espanha, que almejavam ampliar suas

Professor da UNESC. Pesquisador Produtividade CNPq. Pesquisa financiada pela FAPESC e MCT/CNPq. E-mail: alcides@unesc.net 
possessões na busca de metais preciosos e frentes mercantis. As dúvidas sobre os limites do Tratado de Tordesilhas e a busca de uma entrada para os caminhos de Potosí levaram a Coroa Portuguesa, após a Restauração de 1640, a deslocar homens aventureiros e conquistadores para a região do Rio da Prata, com o objetivo de fundar novas povoações. Buenos Aires, fundada em 1580, era o ponto estratégico para as conquistas espanholas, tanto em direção ao sul, região dos pampas e da patagônia, como para o norte, os Andes. Mesmo com as privações que a vila de Buenos Aires sofreu no início, lentamente desenvolveu um pungente comércio baseado na pecuária. Esse cenário levou as expedições portuguesas até as margens do Prata, onde fundaram a Colônia do Sacramento, em 1680, afrontando os interesses da Espanha.

No caminho até o extremo sul, pelo litoral, foram fundadas as povoações de Paranaguá (1648), São Francisco (1658), Desterro (1675) e Laguna (1676), que serviam de fortificações e bases para novas expedições em direção ao sul ou ao interior. A Colônia do Sacramento, fundada pelo governador da Capitania do Rio de Janeiro, D. Manuel Lôbo, cumpria os objetivos da Coroa, que almejava estender o seu território até as margens do Prata, servindo de ponto de comunicação nas bandas meridionais. Por quase 140 anos Sacramento foi palco de conflitos bélicos e diplomáticos entre as duas coroas, que reivindicavam a sua posse, começando pelo Tratado Provincial de Lisboa de 1681 até a independência do Uruguai, em 1828. Sacramento, mais do que uma fortificação militar, tornou-se um importante entreposto comercial na organização e na distribuição do gado que vivia solto nos pampas platinos e gaúchos. Os gados vacum, muar e cavalar foram introduzidos pelos jesuítas, a partir dos Sete Povos das Missões, e se reproduziram livremente nas pradarias gaúchas (HOLANDA, 1989).

O Tratado de Madrid (1750), entre Portugal e Espanha, em boa medida definiu o atual contorno do território brasileiro com a entrega da Colônia do Sacramento à Coroa Espanhola e a incorporação dos Sete Povos das Missões pela Portuguesa. Apesar de serem assinados novos tratados nas décadas seguintes, os principais marcos foram definidos em 1750. Com a incorporação dos Sete Povos, a expulsão dos jesuítas e o extermínio de milhares de indígenas abriram-se as possibilidades de se explorar a pecuária nos pampas gaúchos e no litoral, por meio da comercialização de couro e animais. Com 
a fundação de Rio Grande (1737), de Viamão (1741) e da Capitania de Rio Grande de São Pedro (1760), além da abertura dos primeiros caminhos em direção a São Paulo e da difusão de grandes estâncias de criação de gado, as atividades pecuárias tornaram-se mais relevantes para a Coroa e para a Colônia, que passam a proteger e a ocupar ainda mais o território.

Durante o período colonial, havia três grandes zonas pecuárias no Brasil: os sertões do Nordeste, a parte meridional de Minas Gerais e as planícies do Sul. As capitanias de São Paulo e do Rio de Janeiro eram os dois centros consumidores dos gados criados e abatidos em Minas e no Sul (PRADO JÚNIOR, 1996). Naquelas planícies eram criados, principalmente, os gados vacum, cavalar e muar. Do vacum eram extraídos o couro e a carne para a preparação do charque, ambos exportados; o cavalar, em boa medida, era aproveitado nas próprias estâncias locais para os afazeres diários; o muar (mula), um animal de carga que resiste a cavalgadas de longa distância e que passou a ser reproduzido nas estâncias, tornou-se uma das principais mercadorias gaúchas comercializadas nas feiras paulistas durante os séculos XVIII e XIX.

Segundo Simonsen (1978), a produção pecuária constituiu-se numa atividade econômica cujos rendimentos ficavam incorporados à colônia, ou seja, a acumulação, mesmo sendo lenta, era apropriada por estancieiros e comerciantes locais. Ao contrário das atividades açucareiras, que funcionavam com capitais da metrópole e para as quais eram destinados os maiores proventos. Comparando com as outras atividades comerciais gestadas na colônia, a pecuária foi a maior responsável por estabelecer "elos indestrutíveis na unidade econômica brasileira" (p. 187). Com um pequeno contingente de homens era possível manter uma vasta extensão de criação de gado. A incorporação de novas terras, ao mesmo tempo em que garantia e demarcava o território para a Coroa e, posteriormente, para o Império brasileiro, possibilitava apreender mais gado e valorizava as atividades pecuárias.

A região das Minas Gerais se tornou o primeiro centro consumidor dos muares meridionais. Com a expansão das atividades auríferas no início do século XVIII, localizadas numa região montanhosa e distante do litoral, a mula foi o principal meio de transporte. No seu lombo, do litoral, sobretudo do Rio de Janeiro, subiam alimentos e utensílios e, em direção ao porto, 
desciam os metais preciosos. Com a redução das atividades auríferas no final do século XVIII, foi dado outro direcionamento para o mercado de mulas. São Paulo, que também demandava animais de carga do Sul, com o surgimento e a expansão do complexo cafeeiro, passou a ser o grande consumidor das mulas advindas das pradarias gaúchas. $\mathrm{O}$ animal servia para fazer o transporte do café, além de outras mercadorias, em direção ao porto de Santos, cruzando a íngreme Serra do Mar.

No longo percurso até São Paulo, Sorocaba era o destino final, onde se formou a maior feira de animais da Colônia e, em seguida, do Império, negociando os muares provenientes do Sul e que seguiam para Minas, Rio ou ficavam mesmo em São Paulo. Além dos animais, também eram negociadas diversas mercadorias oriundas do interior paulista. Em Sorocaba, não havia produção nem utilização em larga escala dos muares, ela apenas servia como entreposto comercial dos animais sulinos e de confluência dos fazendeiros e dos comerciantes que buscavam meios de transportes para atender às demanda da produção agrícola e mineral. As feiras eram realizadas no mês de maio e tiveram início por volta de 1733, quando já estava aberto o primeiro caminho que ligava São Paulo ao sul da Colônia (ALMEIDA, 1945).

Durante o período colonial e boa parte do Império, a comunicação entre as vilas do litoral era feita pela via marítima; já a ligação com o interior, por meio da navegação fluvial e dos caminhos. Porém, ligações do interior com o litoral eram todas independentes entre si, criando, segundo Caio Prado Júnior (1996), uma "disposição fragmentária de comunicações", sem as devidas conexões, formando "pequenos sistemas autônomos" (p. 237) de povoamento tanto no litoral como no interior. Era o caso da navegação fluvial nas bacias do Amazonas, do Parnaíba, do São Francisco, do Paraguai e do Paraná, e os caminhos que seguiam para o interior, desenhados pelas bandeiras e pelas monções. Esses caminhos, em boa medida, seguiram os abertos pelos indígenas, como o Caminho de Peabiru, que partia de vários pontos do litoral sul do Brasil em direção ao Paraguai, dirigindo-se para os Andes. O Peabiru tinha várias ramificações, que foram aproveitadas pelos bandeirantes no apresamento de índios e na prospecção de pedras preciosas. As monções seguiam os rios caudalosos em direção ao centro da Colônia, integrando o comércio do planalto central com o do litoral paulista (HOLANDA, 1994). 
A estrada da Mata e a integração regional pelo interior do Brasil meridional

Ao mesmo tempo em que a abertura de caminhos destinados ao escoamento de muares abastecia os centros consumidores que demandavam meios de transporte, também expandia e consolidava a pecuária sulina, fortificando o lado meridional da Colônia, que estava sempre em conflito com a Espanha. Além disso, estabelecia uma comunicação entre as vilas, os entrepostos comerciais e as fortificações ao longo do litoral, começando por Paranaguá, seguindo em direção a São Francisco, Desterro, Laguna, Rio Grande e terminando em Sacramento. A presença de estâncias de proprietários nativos definia o território e aumentava as rendas da Coroa. Portanto, abrir caminhos era um negócio tanto para os fazendeiros e os comerciantes, como para a nobreza reinol.

A historiografia sobre os caminhos e as estradas no Brasil meridional atribui ao bandeirante paulista Bartolomeu Pais de Abreu a primeira iniciativa para abrir o que ligava Curitiba a Sacramento. Em 1719, Paes de Abreu fez todo o percurso pelo mar de Santos até Buenos Aires e organizou uma série de mapas, desenhando a topografia do litoral. Em 1720, propôs ao rei de Portugal a abertura do caminho, porém a empreitada foi, logo após, abandonada e ele seguiu em novas bandeiras pelo interior da Colônia (ALMEIDA, 1945).

Efetivamente, o caminho pelo interior, ligando Sacramento até os Campos Gerais, chegando a Curitiba, foi aberto em 1728 pelo SargentoMor da Cavalaria, Francisco de Souza e Faria. A expedição comandada por Faria partiu de Conventos, na margem do rio Araranguá (atualmente sul de Santa Catarina) e seguiu em direção ao costão da serra. No planalto serrano, tomou a direção do norte, margeando a serra e chegando até próximo das nascentes dos rios Tijucas e Itajaí-Sul. Depois, seguiu em frente, alcançando as proximidades do Rio dos Cachorros, onde hoje está situada a cidade de Curitibanos (atualmente planalto serrano catarinense). Desse ponto em diante, continuou na direção norte, cruzando a mata fechada da serra do Espigão até o Rio Negro. No segundo planalto paranaense os campos são mais abertos, o que facilitou a sua chegada a Curitiba (FARIAS, 1908). Esse caminho ficou conhecido como "Dos Conventos". De Sacramento até as margens do Rio Araranguá, ele era feito pelo litoral que enfrentava várias dificuldades nas travessias dos rios e de suas barras. Mesmo assim, a subida da serra, no interior de Araranguá, dado o seu aclive, também era muito difícil, o que tornava a viagem com homens e gado vacum muito 
demorada e arriscada. Porém, o caminho que segue do Rio dos Cachorros até o Rio Negro e Curitiba parecia ser a melhor opção, mesmo enfrentando uma mata muito fechada (Anexos 1 e 2).

Um novo caminho foi aberto pelo Coronel Cristovão Pereira de Abreu em 1733, que aproveitou parte do caminho de Farias, evitando a subida da serra em direção a leste Dos Conventos. Ele partiu de Viamão (atualmente, Santo Antônio da Patrulha), ganhou os Campos de Vacarias, cruzou o Rio Pelotas e chegou até o planalto serrano, uma vasta área de campos limpos, o que facilitava em muito as grandes cavalgadas. Depois, seguia em frente, passando por onde se situa hoje a cidade de Lages, alcançando o caminho aberto por Farias, cortando a mesma mata fechada até o Rio Negro (INSTITUTO HISTÓRICO E GEOGRÁFICO BRASILEIRO, 1858). Ficou conhecido como o Caminho Viamão-Sorocaba, por onde transitou grande parte das tropas de muares que vinham das estâncias do extremo sul em direção às feiras de Sorocaba para serem vendidos, num primeiro momento, aos negociantes das atividades auríferas das Minas Gerais e, em seguida, ao complexo fluminense e paulista (Anexos 1 e 2).

Num roteiro elaborado pelo Governador da Capitania de Rio Grande do São Pedro do Sul, em 1797, entre Porto Alegre e São Paulo, temos uma detalhada descrição do caminho com suas medições em légua. No final, há um breve resumo do trajeto, que segue abaixo:

Itinerário do Caminho Viamão-Sorocaba em 1797

\begin{tabular}{lcc}
\hline \multicolumn{1}{c}{ Itinerário } & Léguas & km atuais \\
\hline Porto Alegre ao Rio Pelotas & 30 & 145 \\
Rio Pelotas ao mato do Espigão (passando por Lages) & 47 & 227 \\
Sertão (trecho da Estrada da Mata) & 41 & 198 \\
Fim do Sertão a Curitiba & 6 & 29 \\
Curitiba a Registro & 3 & 14,5 \\
Registro a Itapetininga & 74 & 357,5 \\
Itapetininga a São Paulo & 34 & 164 \\
Total & 235 & 1.135 \\
\hline
\end{tabular}

Fonte: Revista do Instituto Histórico Geográfico Brasileiro, 1858. 
A estrada da Mata e a integração regional pelo interior do Brasil meridional

Esse era o caminho das tropas e dos tropeiros. Nas suas margens foram erguidos registros para cobrança de impostos, pousos e fazendas para descanso de homens e animais, vilas que se tornaram cidades e novas estradas. Segundo Sergio Buarque de Holanda, "o tropeiro é o sucessor direto do sertanista e o precursor, em muitos pontos, do grande fazendeiro" (1994, p. 132-133).

Neste artigo, estaremos estudando apenas a trajetória de um trecho da Viamão-Sorocaba, que ficava situado entre a Serra do Espigão e o Rio Negro, hoje, mais precisamente, entre os municípios de Santa Cecília (SC) e Campo do Tenente (PR), que ficou conhecida, após os melhoramentos de 1829, como Estrada da Mata. Destacaremos as iniciativas para sua abertura e seus melhoramentos, o povoamento ao longo das suas margens, seu abandono durante a "era ferroviária", sua definição como uma estrada prioritária no primeiro Plano de Viação de 1944 até sua pavimentação nos anos de 1950.

\section{OBRAS E MELHORAMENTOS NA ESTRADA DA MATA}

Dentro do longo caminho das tropas de Viamão a Sorocaba, a Estrada da Mata correspondia ao trecho mais difícil do percurso, pois estava dentro de uma mata fechada, hoje conhecida com Mata Araucária, com terrenos úmidos, montanhosos e cobertos de riachos. A região estava habitada por índios kaingangs e xoklengs, que se sentiam constantemente ameaçados pelos fazendeiros e tropeiros, que os consideravam selvagens e um estorvo para as tropas que seguiam por suas terras. Ao longo da Estrada, foram travadas várias batalhas, o que se estendeu até o início do século XX, com perdas para ambos os lados, porém foram os índios que viram o seu povo sendo dizimado, reduzindo-se a pequenas comunidades.

Ao norte de Lages, a partir da Serra do Espigão, região conhecida como Campo Alto, até Campo do Tenente, após o Rio Negro, o caminho das tropas quase se fechava nos meses de julho a setembro, quando diminuía a passagem das mulas. Durante todo o século XVIII, a cada período em que se iniciavam as cavalgadas, o trecho da Mata era sempre reaberto pelos tropeiros que seguiam na frente, levando em média 20 dias para atravessar esse trecho de aproximadamente $264 \mathrm{~km}$. Para os estancieiros e os proprietários das tropas, a tarefa de manter o caminho sempre aberto 
não poderia ser dos tropeiros, que perdiam muito tempo com esse trabalho. Diante dessas dificuldades, em 1816, os tropeiros requereram junto a D. João VI providências para abrir uma estrada nesse trecho que apresentava mais dificuldades. As despesas seriam cobertas com a cobrança de uma taxa de 100 réis por cabeça de gado que nela transitasse. Essa proposta agradou tanto aos fazendeiros e aos comerciantes locais, que viam na abertura da estrada a possibilidade de ampliar seus contatos com outras praças comerciais, como à Real Fazenda, que almejava aumentar suas receitas (MOREIRA, 1975; RODRIGUES, 1906).

Em 1820, D. João VI determinou que o capitão e governador da Capitania de São Paulo, João Carlos Augusto Oeynhausen, construísse a estrada solicitada pelos tropeiros. Oeynhausen destinou a João da Silva Machado a tarefa de fazer um amplo levantamento do sinuoso percurso, especificando suas medidas, orçamento e materiais necessários. Em 16 de dezembro de 1820, Machado remeteu-lhe um relatório, expondo suas percepções sobre as necessidades para a abertura da estrada entre Campo do Tenente e Campo Alto. Com uma ampla largura de 66 metros de mata derrubada, o caminho para a passagem dos animais deveria ter 8,8 metros, sendo que, a cada $20 \mathrm{~km}$, seria aberta na mata uma clareira de 366 metros, para pouso e descanso das tropas. Eram 120 rios e seriam construídas pontes apenas nos que apresentavam dificuldades para a travessia. Machado requisitou uma leva de 70 trabalhadores, com renovação constante da mão de obra para evitar desentendimentos entre eles. O prazo previsto e requisitado para seu término foi de 6 anos (ARBIGAUS, 1929).

Conforme solicitado por Machado, as obras tiveram início no dia 26 de março de 1826 e terminaram antes do prazo previsto, em maio de 1829, com um gasto anual de 1:666 $\$ 800$ réis. Durante as obras, intensificaram-se os conflitos com os índios e foram definidos novos locais para povoar os Campos Gerais. Com as obras concluídas, passou-se a fazer a cobrança de 100 réis por animal, com o objetivo de manter a conservação da estrada, para a qual eram utilizados aproximadamente 50 trabalhadores que, no mês de março, faziam a sua limpeza, cortando os brotos de árvores para evitar que a mata fechasse a estrada.

O registro fiscal dos animais era feito em Rio Negro, onde já havia uma capela erguida, criando as condições para fundar, nas suas proximidades, um 
núcleo colonizador. Com o objetivo de manter e conservar a Estrada da Mata e expandir a colonização para o Vale do Rio Negro, João da Silva Machado comandou a vinda de imigrantes, provenientes do Império Germânico, para se instalarem nas margens da estrada. Em 1829, chegaram os primeiros, num total de 238 pessoas; nos anos seguintes, vieram os bucovinos, também provenientes da Germânia, e, mais para o final do século XIX, foi a vez dos poloneses. Esses colonos, com o apoio do Estado, ocuparam a região e, aos poucos, foram-se espalhando para outras localidades do Vale do Iguaçu, fundando novas vilas e mercantilizando a região. A vinda desses primeiros imigrantes para o Brasil, somando-se a outros que havia no Vale do Rio do Sino, estava dentro de um movimento maior, estimulado pelo Governo Imperial, que promoveu no mesmo ano a colonização das Províncias de Santa Catarina, onde fundaram São Pedro de Alcântara, e do Rio Grande do Sul (D'ALMEIDA, 1976; REISEMBERG, 1973).

Dadas as características geofísicas e a densidade da mata, uma das maiores dificuldades da Estrada da Mata era mantê-la em condições de tráfego na época das tropas. Após a conclusão dos trabalhos de abertura, a responsabilidade pela constante limpeza, sobretudo para cortar os novos brotos de árvores e consertar as pontes, ficou sob a incumbência do prefeito da Vila do Príncipe, atual município de Lapa, que, na época, era um importante centro mercantil, dentro dos Campos Gerais, na rota dos tropeiros (SÃO PAULO, 1838). Como alternativa para evitar esse difícil caminho, mesmo com a sua manutenção, o governo da Província de São Paulo, da qual a região ainda fazia parte, determinou a abertura de um novo, proveniente das missões do Rio Grande do Sul e que cortasse os Campos de Palmas, a oeste de Santa Catarina, em direção a Castro. Além de passar por campos mais abertos, iria reduzir em aproximadamente $290 \mathrm{~km}$ o percurso total. Outro fator determinante para os tropeiros era que não havia um registro fiscal na entrada em São Paulo (SÃO PAULO, 1846). O caminho foi aberto e se constitui, ao longo de todo século XIX, como uma alternativa para as tropas que enfrentavam enormes dificuldades no sinuoso trecho da Estrada da Mata.

Para o governo da Província de Santa Catarina, integrar outras regiões com a Estrada da Mata era uma saída estratégica para melhor definir o território catarinense, cuja porção mais a oeste e no planalto norte ainda estava em litígio. A Estrada Lages, em direção ao litoral, colocava a capital 
da província em contato com as tropas e ampliava as relações mercantis entre as duas regiões. Quando foi iniciada a construção da Estrada Dona Francisca, em 1853, partindo de Joinville, seu destino final seria Rio Negro, no encontro com a Estrada da Mata. O mesmo ocorreu com as expedições que partiram das margens do Rio Itajaí-Açu, em direção à serra para encontrar com Curitibanos, colocando as colônias do Vale do Itajaí em contato com o movimento dos tropeiros, que, na época, era um dos mais relevantes do Império. Todos esses caminhos se consolidaram ao longo da segunda metade do século XIX e, mais tarde, constituíram-se em importantes eixos rodoviários de Santa Catarina.

No ano de 1848, o governo provincial catarinense delegou ao Major Antonio Saturnino de Souza e Oliveira a responsabilidade de manter e conservar a Estrada da Mata, no trecho que atravessava o território catarinense. Para tanto, o governo Imperial destinou verbas anuais, na ordem de 4:000\$000 réis, para cobrir os gastos com os serviços de limpeza do terreno, reparos de pontes e aterro de áreas alagadiças (SANTA CATARINA, 1848). Na década seguinte, essas verbas, sob responsabilidade do governo provincial, mantiveram uma regularidade anual de 4:000\$000 réis (SANTA CATARINA, 1856).

\footnotetext{
Na estrada de S. Pedro ao Paraná atravessando Lages, compuseram-se as restingas do Campo Alto, Marombas e Curitibanos, fez-se um novo alterado no passo do Rio das Pedras e roçaram-se as restingas do Canoas na extensão de 2.000 braças [4.400 metros]. Continua-se nos melhoramentos dessa estrada, na qual se tem de fazer as pontes dos rios Correte e das Pedras (SANTA CATARINA, 1858, p. 11).
}

Durante toda a segunda metade do século XIX, o governo catarinense responsabilizou-se pela manutenção do caminho Viamão-Sorocaba, no trecho entre a divisa com o Rio Grande do Sul, do Rio Pelotas até a Serra do Espigão, que compreendia um fragmento do caminho que se situava em áreas mais abertas em campos limpos. Para a Serra do Espigão em diante, mais precisamente do Rio Canoinhas, onde começa a parte da mata fechada, o governo provincial do Paraná designava recursos e homens para a sua manutenção.

Com a criação do Paraná, desmembrado de São Paulo em 1853, sem a definição do território da nova província, começou uma disputa com Santa Catarina, para definir a quem pertenciam as atuais regiões do meio-oeste, 
do oeste e do planalto norte-catarinense, onde estava inserida a Estrada da Mata. Para os melhoramentos do caminho das tropas, o governo paranaense o dividiu em sete seções, começando a primeira em Itararé, na divisa com São Paulo, e terminando a sétima entre o Rio Negro e o Rio Canoinhas, no interior da Estrada da Mata, adentrando em território catarinense, onde havia 13 pontes, 37 pontilhões, 6 açudes, 14 passos nos rios e córregos e 15 pequenos morros (PARANÁ, 1856; PARANÁ, 1860). Era o trecho da Estrada a que Santa Catarina não prestava serviços de melhoramentos.

Em 1857, o governo paranaense mandou construir as pontes sobre o rio Canoinhas, que atualmente passa pelo município de Monte Castelo, e o Itajaí Norte, sendo inspecionadas por Francisco Xavier de Assis, que se responsabilizou por toda a estrada até o início dos anos de 1860: "Na data das últimas informações esta estrada estava transitável, mas, diz o administrador, há ainda necessidade de fazer dos lados dela algumas derrubadas" (PARANÁ, 1858, p. 105). Com algumas obras e melhoramentos, Assis deixou a Estrada "em bom estado desde a Vila do Príncipe até Canoinhas" (PARANÁ, 1862, p. 73). Porém, mesmo com os constantes serviços, a destruição causada pela passagem das tropas e o avanço da mata no período da "entressafra" eram mais velozes e agressivos que os esforços hercúleos para mantê-la transitável.

Destaca-se que, nesse período, começou a ser introduzido no Brasil o sistema de estrada macadamizada, como a Estrada União e Indústria, entre Petrópolis e Juiz de Fora, e a Dona Francisca, no planalto norte-catarinense. A Estrada da Mata era nada mais que uma grande vereda aberta na mata, dando condições apenas para a passagem de gado, animais montados e, com muita dificuldade, para carros de boi. Desde a criação da província, em 1853, até 1865, o governo paranaense já havia investido na Estrada da Mata 105:855 $\$ 560$ réis, o que representava 14,9\% dos recursos destinos às estradas (PARANÁ, 1866). Mesmo assim, nos meados dos anos de 1860, novamente as condições da estrada tornam-se calamitosas, o que levou o governo provincial do Paraná, em 1867, a estabelecer um contrato com Lino de Souza Ferreira, no valor de 3:200\$000 réis, para executar serviços de roçadas e construção de pontes, no trecho entre a Vila do Príncipe e os limites com Santa Catarina (PARANÁ, 1868). Com esse contrato, o governo transferia a responsabilidade para empreiteiros privados, que se encarregariam de manter a Estrada em condições de tráfego. Era uma tarefa de Sísifo. 


\section{ACHEGADA DAS FERROVIAS E OABANDONO DA ESTRADA}

Como a estrada estava ligada diretamente às feiras de Sorocaba, que abasteciam muares para o complexo cafeeiro e os utilizavam para o transporte entre as fazendas e os portos, qualquer mudança que ocorresse na estrutura desse complexo repercutiria no seu fluxo. Essa mudança ocorreu com a chegada das ferrovias. Em 1867, foi inaugurada a Estrada de Ferro Santos-Jundiaí, que ligava parte do interior paulista ao grande porto cafeeiro. E, em 1875, a Estrada de Ferro Sorocabana ampliava essa integração, chegando até a capital paulista. Nos anos seguintes, a construção de novas ferrovias para atender à demanda da produção cafeeira crescia de forma exponencial, interiorizando cada vez mais os caminhos de ferro, não apenas em São Paulo, mas em várias regiões do país. A rápida substituição do lombo das mulas pelos vagões dos trens provocou uma queda acentuada na procura por muares advindos do sul do país. Esse foi o fator determinante que levou ao arrefecimento das feiras de Sorocaba, desdobrando-se na queda do fluxo de tropeiros que passavam pela Estrada da Mata. Abaixo, temos um gráfico, elaborado a partir de Klein (1989), que mostra a trajetória da oferta de muares nas feiras de Sorocaba, entre 1830 e 1880.

Total de muares que chegavam em Sorocaba 1830-1880

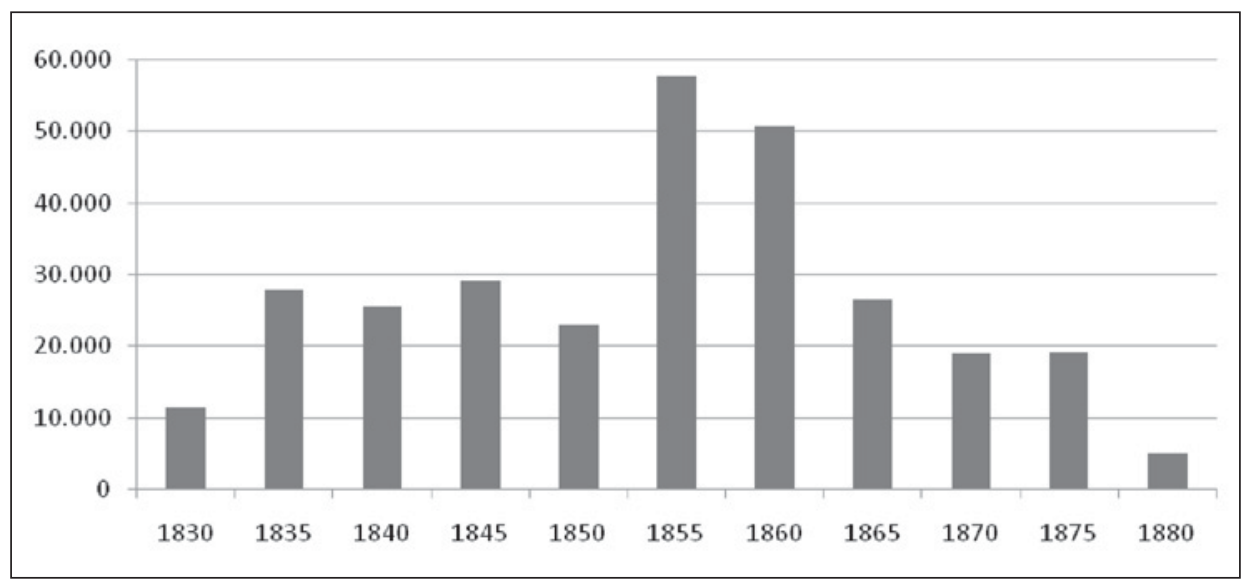

Fonte: Klein, 1989. 
O gráfico é bem ilustrativo e mostra o aumento considerável de muares que entram em Sorocaba nos meados do século XIX, justamente quando começa a expansão do complexo cafeeiro no Rio de Janeiro e em São Paulo, seguindo-se uma queda acentuada após 1865, quando entram em operação as ferrovias paulistas. Enquanto em 1855 chegaram 57.698 muares, em 1880, foram apenas 5.188 (KLEIN, 1989). Almeida (1945) estima que, em 1892, foram apenas 1.000, o que poderia ser resumido a uma ou duas tropas. É diante desse movimento de animais que temos que pensar a trajetória da Estrada da Mata no século XIX: melhoramentos e abandono.

No Paraná, a primeiro trecho ferroviário foi inaugurado em 1885, a Estrada de Ferro Curitiba-Paranaguá, substituindo as mulas que levavam a erva-mate pelos caminhos da Graciosa e de Itupava até os portos de Antonina e Paranaguá. Seus ramais foram estendidos nos anos seguintes para Lapa (1891), Campo do Tenente (1894) e Rio Negro (1895). A chegada dos trilhos a Rio Negro desonerava o governo de despender recursos para as melhorias da Estrada da Mata no trecho que subia até Lapa.

Com a queda acentuada do movimento na Estrada, o seu abandono é quase que "natural" a partir do último quartel do século XIX. Porém, é bom lembrar que ela também era utilizada para integrar Rio Negro a Lapa, passando por Campo do Tenente, em direção ao norte, e Rio Negro a Lages, em direção ao sul. O governo paranaense, que almejava demarcar os territórios contestados por Santa Catarina, também fazia da Estrada um instrumento para as estratégias de expansão dos limites da província. Já o governo catarinense destinava mais esforços na construção de estradas em direção ao planalto serrano. Destacamos a Estrada de Lages a Desterro, que consumia boa parte dos recursos do orçamento provincial para as obras nas vias de comunicação. Além da Estrada Lages-Tubarão, em direção ao litoral sul, e a Estrada de Curitibanos, que partia de Blumenau e avançava para o planalto e tinha como objetivo expandir a colonização a oeste do Vale do Itajaí. Já a Estada Dona Francisca, ligando Joinville a Rio Negro, que promoveria a colonização do planalto norte, era de responsabilidade do Governo Imperial.

Um relatório elaborado por Lamenha Lins, em 1876, declarava que a estrada tinha 97,7 quilômetros entre Rio Negro e o Rio Canoinhas, e se achava em "estado deplorável, sendo necessário a reconstrução de muitas 
pontes e pontilhões e roçada completa" (PARANÁ, 1897). Mesmo em situação de quase abandono, em 1878 foi expedido um oficio ao Governo do Paraná, pelo Inspetor Antonio Manuel da Cunha que solicitava "indispensáveis consertos na Estrada da Mata que sem eles se acha quase intransitável". As obras de reparos foram realizadas no ano seguinte, quando foram aplicados 6:400\$000 réis. Porém, a passagem dos animais ao mesmo tempo em que destruía a estrada, contribuía para mantê-la aberta, o que se reverteu com a queda no fluxo de muares, cuja mata passou a dominá-la efetivamente: "A estrada referida necessita conservação para não se perder as obras públicas existentes em prejuízo do trânsito público" (DIRETORIA DE OBRAS DO PARANÁ, 1882). Entre 1881 e 1885, quando o complexo cafeeiro paulista já estava amplamente integrado por ferrovias, na Estrada da Mata foram gastos apenas $837 \$ 850$ réis em manutenção para reparar estragos feitos em cinco anos.

Em 1891, o governo do Paraná expandia a colonização para a região contestada e fundava a Colônia Federal de Lucena, atual município de Itaiópolis, localizada a $35 \mathrm{~km}$ ao sul de Rio Negro, com a presença de famílias polonesas e ucranianas. Com a queda no movimento das tropas, os gastos com os reparos na Estrada limitavam-se apenas aos trechos mais utilizados pela população regional, como a construção da ponte metálica sobre o Rio Negro, inaugurada em 1896, e as estradas em Lucena, que não estava na rota dos tropeiros.

No quadro abaixo, podemos acompanhar um panorama geral dos melhoramentos que foram realizados na Estrada da Mata e em outras da região, pelo governo paranaense entre 1854 a 1896, destacando-se as obras executadas e os recursos destinados.

Tabela 2: Resumo das despesas efetuadas com os melhoramentos e a construção de estradas na zona ao sul do Rio Negro - 1854-1896

\begin{tabular}{clr}
\hline Anos & \multicolumn{1}{c}{ Obras e reparos realizados } & Valores gastos \\
\hline $1854-1855$ & Na Estrada da Mata & $4: 348 \$ 000$ \\
$1857-1858$ & Na Estrada da Mata & $4: 673 \$ 280$ \\
$1860-1861$ & Na Estrada da Mata & $15: 976 \$ 860$ \\
1863 & Uma ponte na Estrada da Mata & $560 \$ 000$ \\
1867 & Na Estrada da Mata e pontes & $3: 200 \$ 000$ \\
\hline
\end{tabular}


A estrada da Mata e a integração regional pelo interior do Brasil meridional

\begin{tabular}{clr}
\hline Anos & \multicolumn{1}{c}{ Obras e reparos realizados } & Valores gastos \\
\hline 1868 & Na Estrada da Mata e pontes (Rio Itajaí - orçado) & $7: 200 \$ 000$ \\
1869 & Na Estrada da Mata e pontilhões & $1: 253 \$ 000$ \\
$1870-1875$ & Serviços orçados na Estrada da Mata & $20: 000 \$ 000$ \\
$1879-1880$ & Na Estrada da Mata & $6: 400 \$ 000$ \\
$1881-1885$ & Na Estrada da Mata & $837 \$ 850$ \\
1888 & Na Estrada da Mata & $4: 000 \$ 000$ \\
$1889-1893$ & Conservação de outras estradas & $3: 397 \$ 820$ \\
$1894-1896$ & Construção da ponte metálica do Rio Negro & $270: 470 \$ 856$ \\
$1894-1895$ & Conservação de outras estradas & $1: 115 \$ 000$ \\
$1895-1896$ & Estradas em Lucena & $11: 598 \$ 457$ \\
\hline
\end{tabular}

Fonte: PARANÁ, 1897

A tabela acima, combinando com o Gráfico 1, revela o grau de importância que a Estrada da Mata vai perdendo com a queda do comércio de muares em Sorocaba. Entre 1860 a 1875, no auge das feiras paulistas que atendiam à crescente demanda do mercado cafeeiro, foram aplicados 48:213\$860 réis, caindo para 11:237\$850 réis para o período seguinte que se estende até 1896.

Em Santa Catarina, o século XX começa com a aprovação de vários projetos ferroviários. Apesar de muitos não serem executados, alguns marcaram profundamente a vida econômica e social das regiões catarinenses por onde passavam os caminhos de ferro. No meio-oeste, no vale do Rio do Peixe, entre 1907 e 1910, foi construído o trecho faltante da monumental Estrada de Ferro São-Paulo Rio Grande, pondo em contado Porto Alegre com o Rio de Janeiro pelos trilhos dos trens. Em 1906, foi inaugurado o primeiro trecho da Linha São Francisco, que partia de São Francisco do Sul, passava por Joinville, subia a Serra do Mar e chegava até o planalto norte-catarinense. No ano de 1913, essa linha chegou a Rio Negro, na sua margem esquerda, em território catarinense (GOULARTI FILHO, 2009). E, finalmente, conclui seu destino chegando até Porto União. A Estrada de Ferro São Paulo-Rio Grande, a Linha São Francisco e os ramais da Estrada de Ferro Curitiba-Paranaguá colocavam a região em contato com as maiores praças comerciais do Sul e do Sudeste do país, dispensando as morosas e intransitáveis estradas. Estávamos na "era ferroviária". 
A Guerra do Contestado, entre 1912 e 1916, e a Questão dos Limites entre os dois estados, resolvida somente em 1916, com ganho de causa para os catarinenses, colocaram o governo de Santa Catarina em prontidão para ocupar com mais intensidade o planalto norte. Em 1917, foi criado o município de Mafra, na margem esquerda do Rio Negro, e, em 1918, reemancipado o de Itaiópolis, agora em território catarinense. A região fazia parte do complexo ervateiro, que incluía Canoinhas e Porto União, como centro de cultivo, beneficiamento e comercialização da erva-mate. O complexo ervateiro utilizava as vias de comunicações e os meios de transportes regionais para o escoamento da produção, ligando as áreas produtoras às casas comerciais e aos portos no litoral. Pelos rios Iguaçu e Negro era feita a navegação fluvial ligando Porto União e Caninhas até Mafra, de onde a erva seguia pela Estrada Dona Francisca e pela Linha São Francisco, em direção a Joinville, para ser beneficiada e, em seguida, exportada pelo porto de São Francisco (GOULARTI FILHO, 2010).

Portanto, com a consolidação desse complexo ervateiro, que combinava vários sistemas de transporte, a Estrada da Mata reduziu ainda mais o seu grau de importância como elemento integrador e demarcador de território. Os pequenos trechos que ainda remanesciam da estrada eram utilizados para ligar pequenas comunidades ou fazendas instaladas ao longo da "antiga estrada". As carroçáveis e macadamizadas, de pequena extensão, de responsabilidade das prefeituras municipais. faziam a ligação entre comunidades locais, e as estaduais, que passavam por dois ou mais municípios. Os moradores passaram a utilizar caminhos menos sinuosos e íngremes, como a estrada entre Papanduva, Major Vieira, Bela Vista e Canoinhas.

\section{A VELHA ESTRADA E A NOVA RODOVIA}

As ferrovias e a navegação fluvial e de cabotagem marítima foram as principais modalidades de transportes no Brasil até os anos de 1930. O advento e a difusão dos automóveis, das caminhonetes e dos caminhões obrigaram o Estado brasileiro a voltar parte da sua política de viação e obras públicas para as rodovias. O país já era cortado por longos caminhos no interior, alguns se tornaram estradas com vários melhoramentos, mas, com a chegada dos trens, muitos foram abandonados. Esses caminhos 
foram retomados e serviram como guias para orientar as rotas das novas rodovias que começaram a ser abertas nos anos de 1920, e transformados em autopistas nos anos de 1950. Como exemplo, temos a ligação entre São Paulo e Rio de Janeiro, inaugurada em 1928 e transformada na Rodovia Presidente Dutra em 1951. Durante o governo de Washington Luiz (1926-1930), foi criada, em 1927, a Comissão de Estradas de Rodagem Federais, que ficou encarregada de elaborar um plano rodoviário para o país. Como base para esse plano, foram utilizados esboços elaborados pelos engenheiros Joaquim Catambri, de 1926, e Luiz Schnnor, de 1927. Em linhas gerais, no Plano da Comissão, o país deveria ser cortado por grandes eixos longitudinais e transversais. Especificamente para o sul, havia a Linha Interna de São Paulo, Curitiba, Lages e Porto Alegre (MINISTÉRIO DOS TRANSPORTES, 1974).

Antes da abertura da atual BR-116, ligando Curitiba a Porto Alegre, passando por Rio Negro e Lages, o trajeto era utilizado pelos automóveis. O primeiro saía de Curitiba, descendo a Serra do Mar em direção a Joinville, e continuava até Itajaí, de onde entrava em direção ao oeste, para Blumenau, dali partia para o interior, passando por Rio do Sul até chegar a Curitibanos, ou seja, fazendo o percurso da atual BR-470. De Curitibanos, seguia-se para Lages, que já estava integrada com Vacarias e Porto Alegre. O segundo trajeto seria seguir, a partir de Itajaí, em direção a Florianópolis e ao sul, pelo litoral da antiga Estrada da Praia, atual BR-101. Havia a ligação da capital catarinense até Laguna e, depois, até Araranguá, pelo litoral, ou entrando em direção a Orleans, seguindo para Urussanga e, novamente, em Araranguá, pela rota dos imigrantes. De Araranguá seguia em direção a Torres, cuja parte do caminho era feita na beira mar até Tramandaí e, depois, por estradas gaúchas até Porto Alegre (NETTO, 1942).

Claro que, antes da abertura da atual BR-116, ligando Curitiba a Porto Alegre, passando por Rio Negro e Lages, o trajeto utilizado pelos automóveis poderia ser duplo. O primeiro saía de Curitiba, descendo a Serra do Mar em direção a Joinville, e continuava até Itajaí. De lá, entrava em direção ao oeste para Blumenau, de onde se partia para o interior, passando por Rio do Sul até chegar a Curitibanos, ou seja, fazendo o percurso da atual BR-470. De Curitibanos seguia-se para Lages, que já estava integrada com Vacarias e Porto Alegre. O segundo trajeto seria seguir a partir de Itajaí em 
direção a Florianópolis, rumo ao sul pelo litoral na antiga Estrada da Praia, atual BR-101. Havia a ligação da capital catarinense até Laguna e, depois, até Araranguá, pelo litoral, ou entrando em direção a Orleans, seguindo para Urussanga e, novamente em Araranguá, pela rota dos imigrantes. De Araranguá seguia em direção a Torres, cuja parte do caminho era feita na beira mar até Tramandaí e, depois, seguia por estradas gaúchas até Porto Alegre (NETTO, 1942).

Nos anos de 1920 e 1930, ainda compensava fazer essa viagem pela Estrada de Ferro São Paulo-Rio Grande ou pelos navios da Companhia Nacional de Navegação Costeira e da Companhia de Navegação Lloyd Brasileiro, pois seria uma viagem menos aventureira. Porém, a proliferação dos automóveis, da indústria automobilística e a obsolescência das ferrovias e da navegação obrigaram o Estado a repensar sua política de transporte e de integração nacional.

Em 1934, Getúlio Vargas, por meio do Decreto n. 24.497, de 29 de junho, aprovou o primeiro Plano Geral de Viação Nacional, que buscava atender às "conveniências nacionais de ordem política, econômica e militar, em relação à rede de viação nacional", além de "coordenar os diversos sistemas de viação". O Plano reforçava o caráter ferroviário, mas abria a possibilidade de combinar com estradas de rodagem e navegação fluvial. $\mathrm{Na}$ verdade, o Plano inaugurou uma nova fase com a centralização das políticas de transportes, cujas estratégias não poderiam ser mais pensadas e executadas de forma fragmentada pelas unidades federativas.

Dentro do novo espírito da época, que estava fundado no Estado Nacional, em 1937 foi criado o Departamento Nacional de Estradas de Rodagem (DNER), que apresentou, no mesmo ano, o Plano Rodoviário, cuja ligação entre Curitiba e Porto Alegre se daria passando por Rio Negro e Lages. Porém, a execução do plano estava inviabilizada por falta de recursos financeiros. Essa situação se reverteu quando foi definitivamente aprovado o Plano Rodoviário Nacional, por meio do Decreto-Lei n. 15.093, de 23 de março de 1944, e com a criação do Fundo Rodoviário Nacional (FRN) em 1945, pelo Decreto-Lei n. 8.463, de 27 de dezembro, que também garantiu autonomia técnica e financeira para o DNER.

O Fundo transformou-se em uma poderosa alavanca para impulsionar a expansão rodoviária no país, implementando as diretrizes do Plano 
de 1944, cujas bases, em larga medida, serviram como referência para os demais planos rodoviários, pois definiam os grandes eixos nacionais. Em direção ao sul, foi reforçada a necessidade de fazer a ligação Curitiba a Porto Alegre por cima da serra, ou seja, passando por Rio Negro, Lages e Vacarias. Esse trecho era parte integrante da Rodovia Getúlio Vargas, que partia de Belém (PA) e seguia em direção ao Nordeste, ao Sudeste e ao Sul, terminando na fronteira com o Uruguai na cidade de Jaguarão (RS), uma extensão de $5.049 \mathrm{~km}$. O trecho compreendido entre Rio de Janeiro e Jaguarão, por cima da serra, ficou designado como BR-2, numa extensão de $1.989 \mathrm{~km}$ (RODOVIA, 1958).

O Decreto-Lei n. 8.463/1945 também definiu um conjunto de obras prioritárias que as foram contempladas no Programa de Construções e Melhoramentos de Primeira Urgência dos troncos do Plano Rodoviário Nacional, no qual estavam quinze rodovias, sendo que dez trechos eram parte integrante da Rodovia Getúlio Vargas, entre eles a construção do trecho Curitiba a Lages e melhoramentos de Lages a Porto Alegre.

No primeiro estudo realizado pelo DNER para o trecho Curitiba a Lages, em 1943, foi sugerido o Traçado Direto, que partiria de Curitiba (Atuba) e seguiria em direção a São Bento do Sul-Bonsucesso-Taió-Passo Velho-Lages, atingindo 348,2 km, deixando Rio Negro de lado. Porém, quando as obras foram iniciadas, a partir de Curitiba, elaboram-se outras propostas que, apesar de serem mais extensas, com 365,6 km, tinham um percurso menos sinuoso e passariam por Rio Negro. No trajeto, a rodovia atravessaria três bacias hidrográficas (Canoas, Itajaí-Norte e Itajaí-Sul) (RODOVIA, 1949)

As obras foram divididas em duas grandes frentes: Curitiba a Santa Cecília, com $254 \mathrm{~km}$, incluindo a Serra do Espigão, ficaria sob responsabilidade do DNER, o trecho seguinte, até Lages, com $112 \mathrm{~km}$, com o $2^{\circ}$ Batalhão Rodoviário. O DNER, entre 1944 e 1945, construiu 64 km e, entre 1946 a 1948, mais $152 \mathrm{~km}$, faltando apenas $39 \mathrm{~km}$ para chegar a Santa Cecília. O $2^{\circ}$ Batalhão, até 1949 , já tinha concluído $74 \mathrm{~km}$ e faltavam mais 38 para chegar a Santa Cecília. 
Quadro 1: Rodovia Curitiba-Lages: situação dos serviços em 31/03/1949

\begin{tabular}{|c|c|c|c|c|}
\hline Trechos & $\begin{array}{c}\mathrm{km} \\
\text { construídos }\end{array}$ & $\begin{array}{c}\mathrm{km} \text { em } \\
\text { construção }\end{array}$ & $\begin{array}{c}\mathrm{km} \\
\text { total }\end{array}$ & Observações \\
\hline DNER & & & & \\
\hline Curitiba-Rio Negro & 111,4 & & 111,4 & Revestimento concluído \\
\hline Rio Negro-Fuck & 104,2 & & 104,2 & Revestimento adiantado \\
\hline Fuck-Santa Cecília & & 38,0 & 38,0 & Construção adiantada \\
\hline $2^{\circ}$ Batalhão Rodoviário & & & & \\
\hline Santa Cecília-km 74 & & 38,0 & 38,0 & \\
\hline Km 74 - Lages & 74,0 & & 74,0 & Revestimento concluído \\
\hline Total & 289,6 & 76,0 & 365,6 & \\
\hline
\end{tabular}

Fonte: Revista Rodovia, abril, 1949.

O trecho com maior grau de dificuldades foi a Serra do Espigão, que empregou, na época, em torno de 4.000 trabalhadores. Como ainda não havia no Brasil grandes empreiteiras capazes de assumirem por completo a construção de rodovias, as tarefas eram realizadas e coordenadas pelo Estado, seja por meio do DNER ou do Exército. Todo o equipamento, envolvendo tratores, escavadeiras, motos-niveladoras, rolos-compressores, compressores e caminhões, pertencia ao Estado. As empreiteiras assumiam a execução de pequenas obras nos serviços finais, principalmente quando a rodovia estava sendo pavimentada.

A BR-2 não seguiu os mesmos passos da Estrada da Mata. Na verdade, seria algo quase impossível fazer o mesmo trajeto, uma vez que o antigo caminho dava muitas voltas, subia e descia montanhas, passava por terrenos alagadiços e cruzava os rios nas áreas mais baixas. Em alguns trechos, as duas estradas se cruzaram, mas logo em seguida se distanciavam novamente.

Em 1956, a meta de conclusão da BR-2 foi incluída no Plano Quinquenal de Obras Rodoviárias Federais elaborado pelo DNER e que fazia parte do Plano de Metas do governo Juscelino Kubitschek, que se propôs abrir 15 mil quilômetros de rodovias. A definição dessa meta garantiu para a BR-2 verbas orçamentárias anuais, o que permitiria a sua conclusão até o final da década (RODOVIA, 1959).

Finalmente, no dia 6 de agosto de 1959, o Presidente Juscelino Kubitschek inaugurou mais um trecho da BR-2, entre Curitiba e Lages, completamente pavimentado. Foram dois atos solenes, o primeiro em Curitiba e o 
segundo em Lages. Com a sua conclusão, o percurso entre as duas cidades, antes feito por Joinville-Itajaí-Blumenau-Rio do Sul-Curitibanos, passou de $496 \mathrm{~km}$ para $366 \mathrm{~km}$, sem contar que o primeiro percurso era muito sinuoso e não pavimentado (RODOVIA, 1959). Na época, era a rodovia mais moderna em Santa Catarina, que ainda carecia de outras, pavimentadas. Nem Florianópolis, a capital do Estado, ainda era alimentada modernas estradas.

O trecho entre Porto Alegre e Caxias do Sul, também pela BR-2, já havia sido inaugurado em 17 de abril de 1959, porém, o seguinte até Vacaria, seguindo para Lages foi entregue oficialmente ao público em 1962. Com a conclusão das obras, já era possível fazer os 707 km, entre Curitiba e Porto Alegre, por cima da serra, por vias totalmente asfaltadas em aproximadamente 10 horas. Era o tempo gasto pelos tropeiros em dois ou três quilômetros nos difíceis caminhos da Estrada da Mata.

\section{THE $E S T R A D A D A$ MATA AND THE REGIONAL INTEGRATION IN THE HINTERLAND OF SOUTHERN BRAZIL}

\section{Abstract}

The aim of this paper is to describe and analyze the integration of southern Brazil from the country and the opening and improvements of the Estrada da Mata located on the plateau north of Santa Catarina and Parana southeast of Lages (SC) to Campo do Tenente (PR), which was part integral of the troops way between the Viamão and Sorocaba. We will discuss the history of Estrada da Mata since the beginning of its improvements, in 1829, through its abandonment, the late nineteenth and early twentieth century's, until the inclusion of more general in its path of Plano de Viação 1944, which culminated with the opening of all paved a new road between Curitiba and Lages opened in 1959. The article is divided into four topics: a) expansion of the boundaries and pioneering $b$ ) works and improvements at Estrada da Mata, c) the arrival of the railroads and the abandonment of the road, and d) the old road and new highway.

Keywords: Roads, history, economy, integration, drovers.

JEL Classification: N7; R41. 


\section{FONTES E REFERÊNCIAS}

\section{Livros e artigos}

ARBIGAUS, Leonardo. Centenário da colonização alemã Rio NegroMafra 1829-1929. Curitiba: Editora Olivero, 1929.

D'ALMEIDA, Raul de. História de Rio Negro. Rio Negro: Editora do Autor, 1976.

GOULARTI FILHO, Alcides. A Estrada de Ferro São Paulo-Rio Grande na formação econômica regional em Santa Catarina. Geosul. Florianópolis: UFSC/CFH, V. 24, N. 48, JUL-DEZ, 2009.

A Estrada Dona Francisca na formação econômica do planalto norte de Santa Catarina. Anais do II Congreso Latinoamericano de Historia Económica. Cidade do México: UNAM/AMHE, 2010.

HOLANDA, Sérgio Buarque de. A Colônia do Sacramento e a expansão no extremo sul. In: HOLANDA, Sérgio Buarque de. História geral da civilização brasileira. Rio de Janeiro: Bertand do Brasil, 1989.

KLEIN, Herbert S. A oferta de muares no Brasil central: o mercado de Sorocaba, 1825-1880. Estudos Econômicos. São Paulo: USP/FEA, v. 19, n. 2, maio-ago, 1989.

MINISTÉRIO DOS TRANSPORTES. Planos de Viação: evolução histórica 1808-1973. Brasília: Coselho Nacional de Transporte, 1974.

MOREIRA, Júlio Estrela. Caminhos das Comarcas de Curitiba e Paranaguá. Curitiba: Imprensa Oficial, 1975.

PRADO JÚNIOR, Caio. Formação do Brasil contemporâneo. São Paulo: Brasiliense: 1996. 
RIESEMBERG, Alvir. A instalação humana no Vale do Iguaçu. Curitiba: Editora do Autor, 1973.

RODRIGUES, Manuel Coelho. Questões de limites entre os estados do Paraná e Santa Catarina. Rio de Janeiro: Olympio de Campos, 1906.

SIMONSEN, Roberto C. História econômica do Brasil 1500-1820. São Paulo: Companhia Editora Nacional, 1978.

\section{Revistas}

ALMEIDA, Aluisio de. Os caminhos do sul e a feira de Sorocaba. Revista do Instituto Histórico e Geográfico Brasileiro. Rio de Janeiro: Imprensa Nacional, v. 186, 1945.

A RODOVIA. Rodovia Curitiba-Lages. Rio de Janeiro, v. 11, abril, 1949.

Terminar a BR-22 e um pequeno trecho da BR-2 significa concluir a "Rodovia Getúlio Vargas". Rio de Janeiro, v. 20, dezembro, 1958 .

- Entregue oficialmente ao tráfego pelo DNER o trecho Porto Alegre-Caxias do Sul (BR-2). Rio de Janeiro, v. 21, julho, 1959.

Rodovia Curitiba, PR-lages, SC (BR-2). Rio de Janeiro, v. 21 , outubro, 1959

INSTITUTO HISTÓRICO E GEOGRÁFICO BRASILEIRO. Itinerário. Rio de Janeiro, v. 31, 1858.

FARIAS, Francisco de Souza e. Dada ao P. M. Diogo Soares sobre a abertura do novo caminho pelo piloto José Ignacio, que foi e acompanhou em todo ele ao mesmo Sargento Mor Francisco de Souza e Farias. Instituto Histórico e Geográfico Brasileiro. Rio de Janeiro: Imprensa Nacional, n. 79, 1908. 
NETTO, Américo R. O caminho de S. Paulo ao extremo sul. A Rodovia. Rio de Janeiro, v. 6, janeiro, 1943.

\section{Relatórios e ofícios}

DIRETORIA DE OBRAS DO PARANÁ. Ofício de Inspetor Antonio Manuel da Cunha. Arquivo Público do Paraná, 1882.

PARANÁ. Relatório apresentado à Assembléia Legislativa Provincial do Paraná pelo Vice-Presidente Henrique Beaurepaire Rohan. Curitiba: Tipografia de Martins Lopes, 1856. Disponível em <http://www.crl.edu/ brazil> Acesso em: fevereiro de 2011.

. Relatório apresentado ao Presidente da Província do Paraná Francisco Liberato de Matto pelo Vice-Presidente José Antonio Vaz de Carvalhaes. Curitiba: Tipografia de Martins Lopes, 1858. Disponível em <http://www.crl.edu/brazil > Acesso em: fevereiro de 2011.

Relatório apresentado à Assembléia Legislativa Provincial do Paraná pelo Presidente José Francisco Cardoso. Curitiba: Tipografia de Martins Lopes, 1860. Disponível em $<$ http://www.crl.edu/brazil $>$ Acesso em: fevereiro de 2011.

Relatório apresentado à Assembléia Legislativa Provincial do Paraná por Antonio Barbosa Gomes Nogueira. Curitiba: Tipografia Correio Oficial, 1862. Disponível em $<$ http://www.crl.edu/brazil $>$ Acesso em: fevereiro de 2011.

Relatório apresentado à Assembléia Legislativa Provincial do Paraná pelo Presidente André Augusto de Pádua Fleury. Curitiba: Tipografia de Martins Lopes, 1866. Disponível em <http://www.crl.edu/ brazil> Acesso em: fevereiro de 2011. 
Relatório apresentado à Assembléia Legislativa Provincial do Paraná pelo Presidente José Feliciano Horta de Araújo. Curitiba: Tipografia de Martins Lopes, 1868. Disponível em <http://www.crl.edu/ brazil> Acesso em: fevereiro de 2011.

Relatório da Secretaria de Estado dos Negócios de Obras Públicas e Colonização apresentado ao Governador do Paraná pelo Engenheiro Candido Ferreira de Abreu. Curitiba: Tipografia da Livraria Econômica, 1897.

SANTA CATARINA. Relatório apresentado à Assembléia Legislativa Provincial de Santa Catarina Presidente Antero José Ferreira de Britto. Desterro: Tipografia Provincial da Cidade de Desterro, 1848. Disponível em $<$ http://www.crl.edu/brazil $>$ Acesso em: fevereiro de 2011.

Relatório apresentado à Assembléia Legislativa Provincial de Santa Catarina Presidente João José Coutinho. Rio de Janeiro: Tipografia Universal Laemmert, 1856. Disponível em $<$ http://www.crl.edu/ brazil > Acesso em: fevereiro de 2011.

Relatório apresentado à Assembléia Legislativa Provincial de Santa Catarina Presidente João José Coutinho. Desterro: Tipografia Catarinense, 1858. Disponível em $<$ http://www.crl.edu/brazil $>$ Acesso em: fevereiro de 2011.

SÃO PAULO. Discurso do Presidente da Província de São Paulo Bernardo Jose Pinto Gavião Peixoto. São Paulo: Tipografia do Governo, 1838. Disponível em $<\mathrm{http}$ ://www.crl.edu/brazil $>$ Acesso em: fevereiro de 2011.

Relatório apresentado à Assembléia Legislativa Provincial de São Paulo Presidente Manuel da Fonseca Lima e Silva. São Paulo: Tipografia de Silva Sobral, 1846. Disponível em <http://www.crl.edu/ brazil> Acesso em: fevereiro de 2011. 


\section{Decretos}

BRASIL. Decreto-Lei 15.093 de 23 de março de 1944. Brasília: Senado Federal. Disponível em: <http://www6.senado.gov.br/sicon> Acesso em fevereiro de 2011.

Decreto-Lei 8.463 de 27 de dezembro 1945. Brasília: Senado Federal. Disponível em: <http://www6.senado.gov.br/sicon $>$ Acesso em fevereiro de 2011.

Decreto 24.497 de 29 de junho de 1934. Brasília: Senado Federal. Disponível em: <http://www6.senado.gov.br/sicon> Acesso em fevereiro de 2011. 
ANEXO 1: CAMINHOS DAS TROPAS NO BRASIL MERIDIONAL

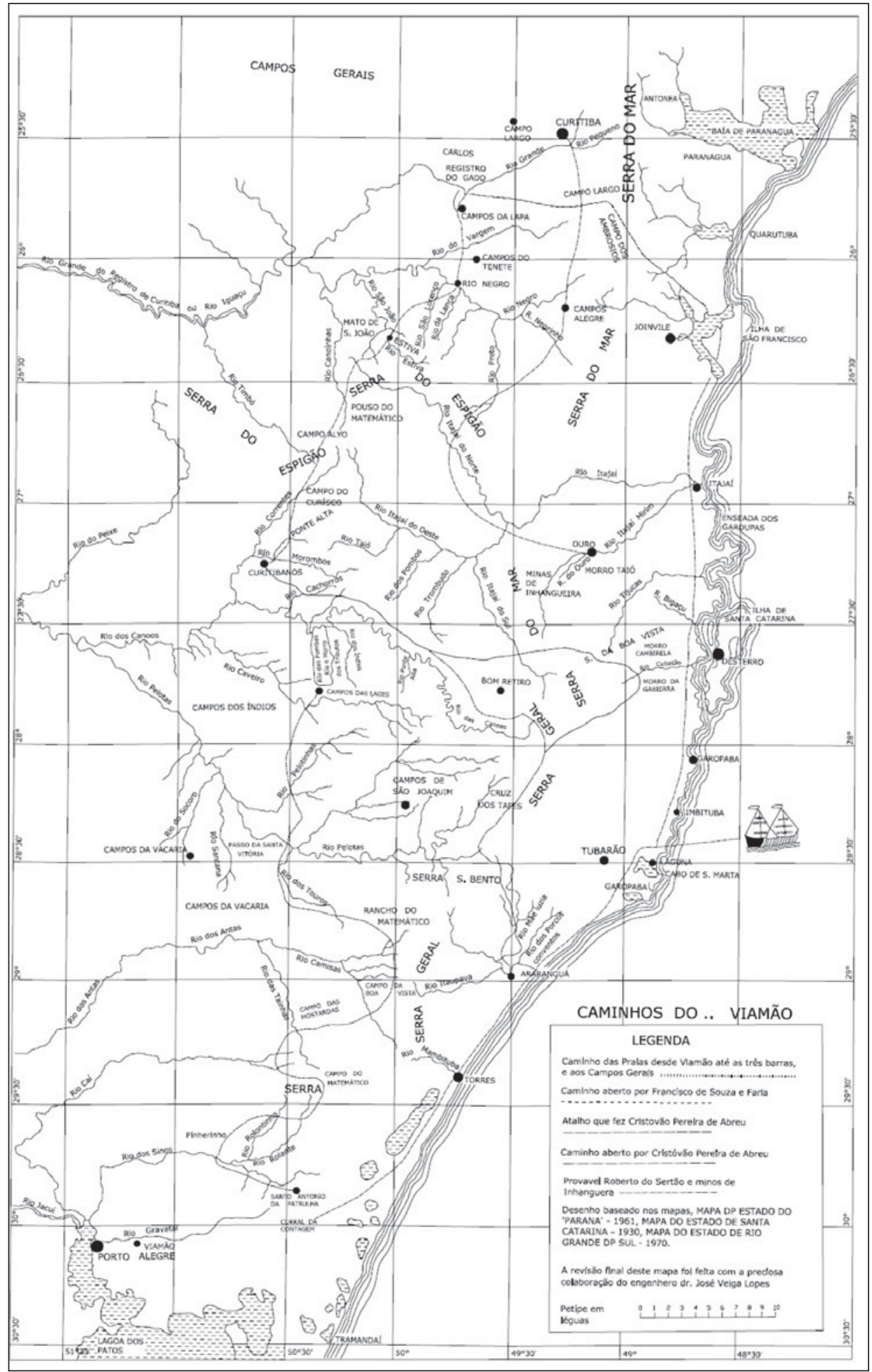

Fonte: MOREIRA, Júlio Estrela. Caminhos das Comarcas de Curitiba e Paranaguá. Curitiba: Imprensa Oficial, 1975. 
ANEXO 2: ESTRADA DA MATA DENTRO DO CAMINHO VIAMÃOSOROCABA

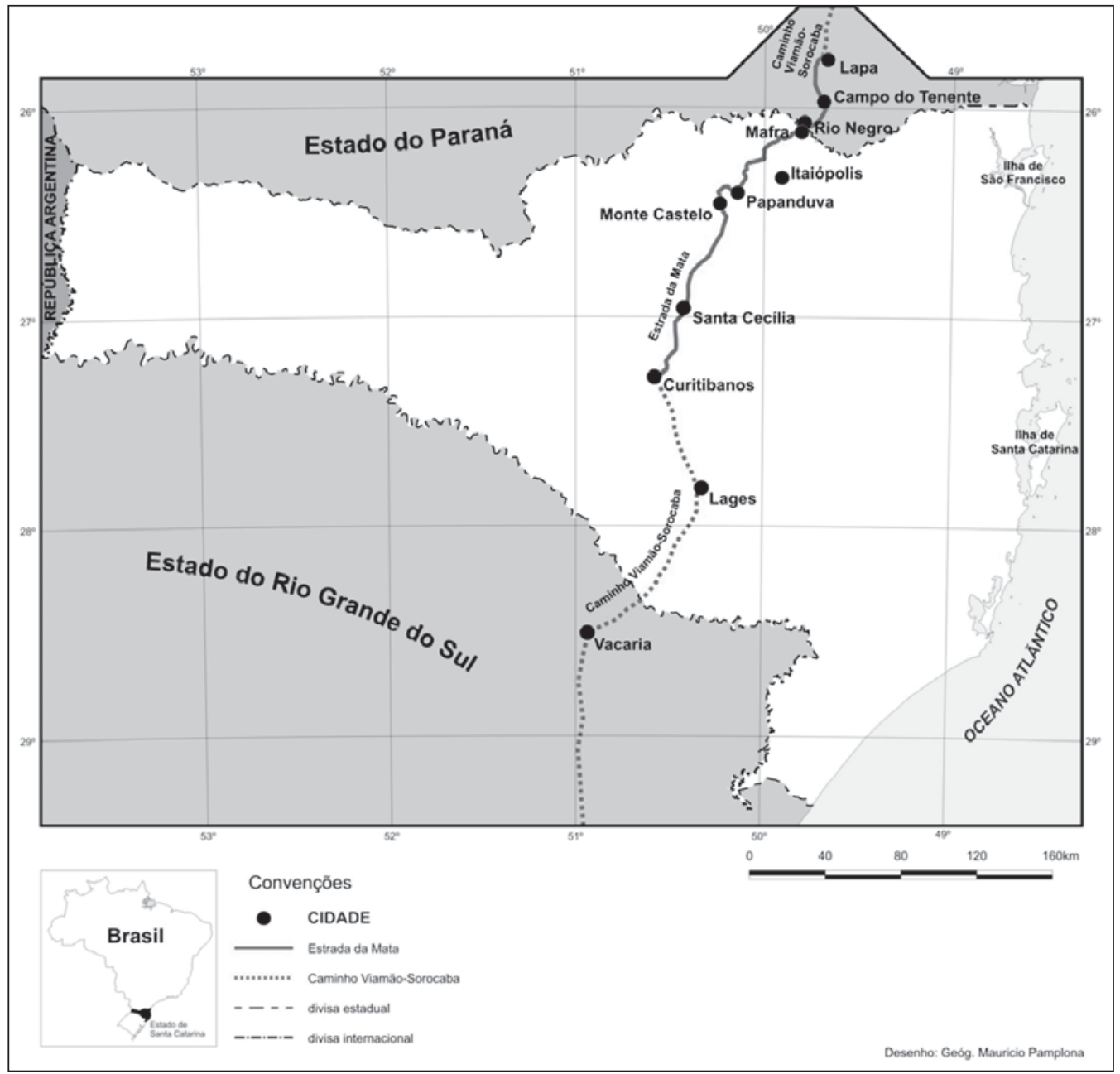

